Miami Nature Biotechnology Short Reports

TheScientificWorld (2001) 1(S3), 108SR

ISSN 1532-2246; DOI 10.1100/TSW.2001.132

\title{
HIBERNATION, A MODEL OF NEUROPROTECTION
}

\author{
Fang Zhou*, Xiongwei Zhu', Mark A. Smith ${ }^{\dagger}$, Rudy J. Castellani ${ }^{\dagger}$, Raphaela \\ Stimmelmayr, George Perry ${ }^{\dagger}$, and Kelly L. Drew
}

Institute of Arctic Biology and Department of Chemistry and Biochemistry, University of Alaska Fairbanks, Box 757000, Fairbanks, AK 99775 and Institute of Pathology, CaseWestern Reserve University, 2085 Adelbert Rd. Cleveland, OH 44106 *ftfz@uaf.edu

INTRODUCTION. Hibernation, a natural model of tolerance to "cerebral ischemia", represents a state of pronounced fluctuation in cerebral blood flow where no brain damage occurs (1). Numerous neuroprotective aspects may contribute in concert to such tolerance. The purpose of this study was to determine if hibernating brain tissue is tolerant to penetrating brain injury modeled by insertion of microdialysis probes.

METHODS. Guide cannulae were surgically implanted in striatum of arctic ground squirrels before any of the animals began to hibernate. Microdialysis probes were then inserted in some animals after they entered hibernation and in others while they remained euthermic. After 3 days implantation of microdialysis probes, the brain tissue from hibernating and euthermic animals was examined by hematoxylin and eosin ( $\mathrm{H} \& \mathrm{E})$ stain and immunocytochemical identification of activated microglia, astrocytes and HO-1 immunoreactivity. Total white blood cell counts were performed on both hibernating and euthermic animals to assess leukocytopenia.

RESULTS. White blood cell counts decrease from $6357 \pm 2739 / \mathrm{mm}^{3}$ in euthermic animals to $456 \pm 98 / \mathrm{mm}^{3}$ in hibernating animals (mean $\pm S D, n=8-10, p<0.0001$ main effect of state). Examination of $\mathrm{H} \& \mathrm{E}$ stained tissue sections indicated obvious histological changes, including reactive astrocytosis, microglial activation, macrophage infiltrate, and axonal swellings around the probe track in euthermic animals while there was no significant cellular tissue response around the probe track in hibernating tissue. 


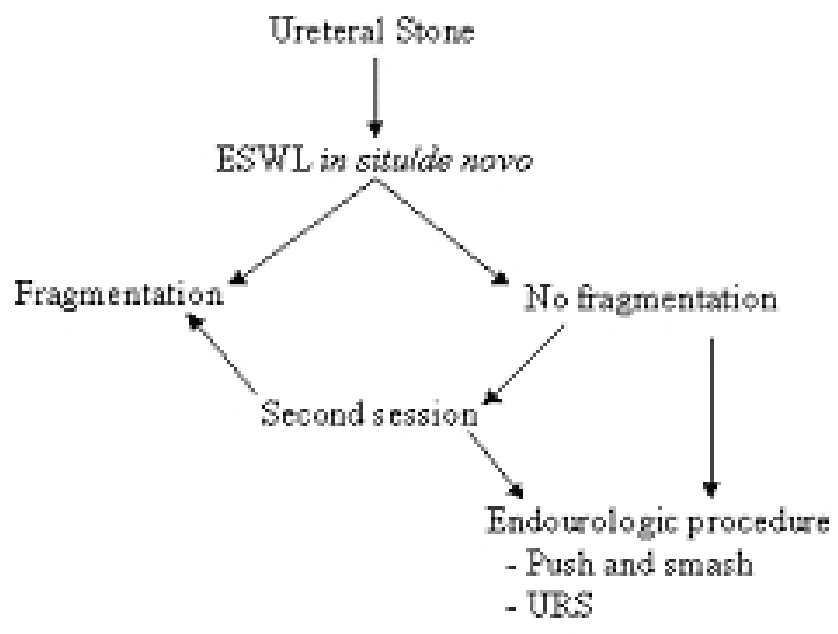

Fig. 1. Activated microglia identified by RCA-1 stain. Scale bar $=100 \mu \mathrm{m}$.

Activated microglia (Fig. 1) and astrocytes, identified by RCA-1 binding and GFAP immunoreactivity, respectively, was more intense around the probe tracts (arrow) in euthermic animals compared to hibernating animals. Hemeoxygenase-1 (HO-1) immunoreactivity, a marker of oxidative stress response induction, was dramatically attenuated around probe tracks in hibernating animals compared to euthermic controls.

DISCUSSION. The present results revealed by histopathological analysis suggest that hibernation is neuroprotective. In euthermic brain tissue the typical inflammatory response was evidenced by the presence of activated microglia and astrocytes and the oxidative stress response. However, these responses were profoundly suppressed in hibernating animals. The significant degree of protection during hibernation likely results from a combination of neuroprotective aspects, including hypothermia, leukocytopenia and an increase in extracellular concentrations of ascorbate during hibernation.

ACKNOWLEDGEMENT. This work was supported by the American Heart Association (AHA grant 98-AK-301), a UAF PSPF grant to K.L.D. The National Institutes of Health (grant NS38648 to M.A.S) and NS41069-01 SNRP funded in part by NINDS, NIMH and NCRR.

\section{REFERENCES.}

1. Lyman, C.P. (1948) J. Exp. Zool. 109, 55-78

2. $\quad$ Snapp, B.D. and Heller, C. (1981) Physiol. Zool. 54, 297-307

3. Frerichs, K.U., Smith, C.B., Brenner, M., et al. (1998) Proc. Natl. Acad. Sci. U S A 95(24), 14511-14516

4. Drew, K.L., Osborne, P.G., Frerichs, K.U., et al. (1999) Brain Res. 851(1-2), 1-8 


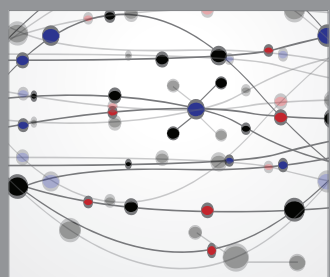

The Scientific World Journal
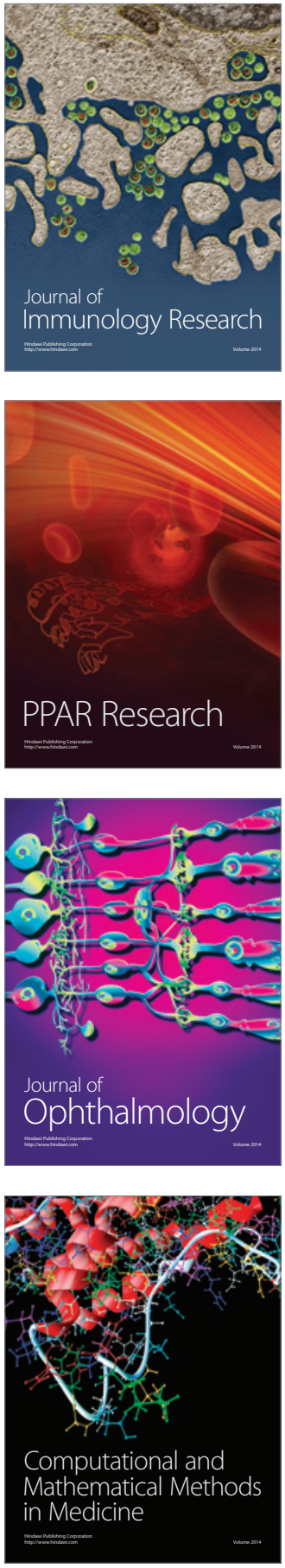

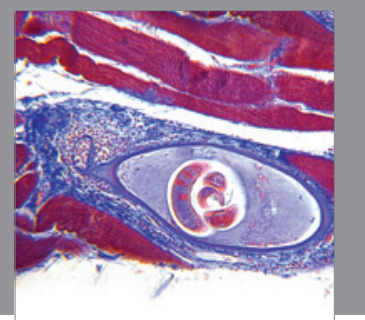

Gastroenterology

Research and Practice
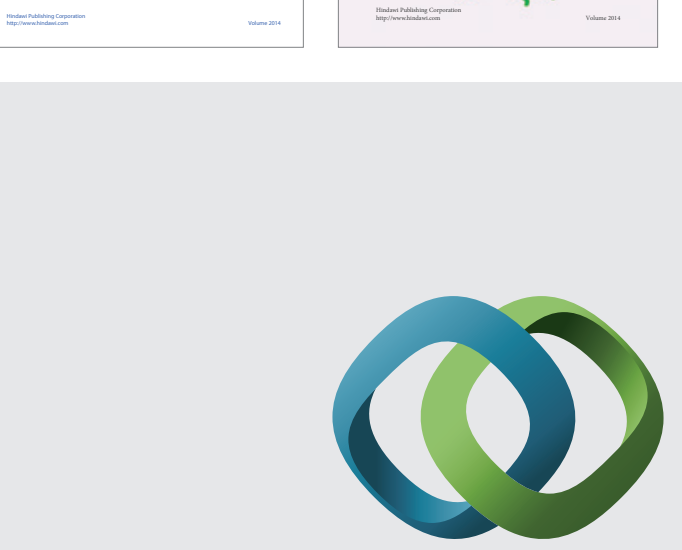

\section{Hindawi}

Submit your manuscripts at

http://www.hindawi.com
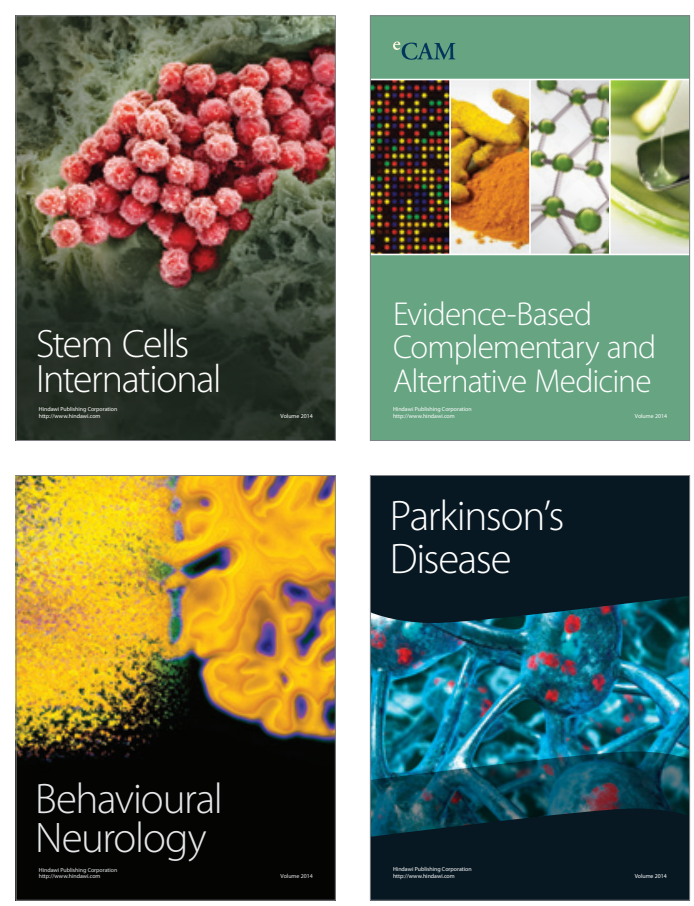

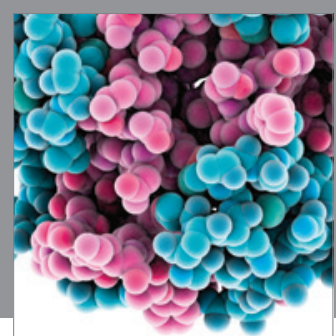

Journal of
Diabetes Research

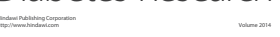

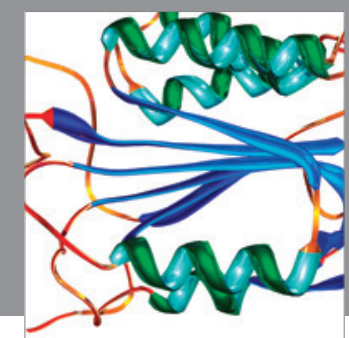

Disease Markers
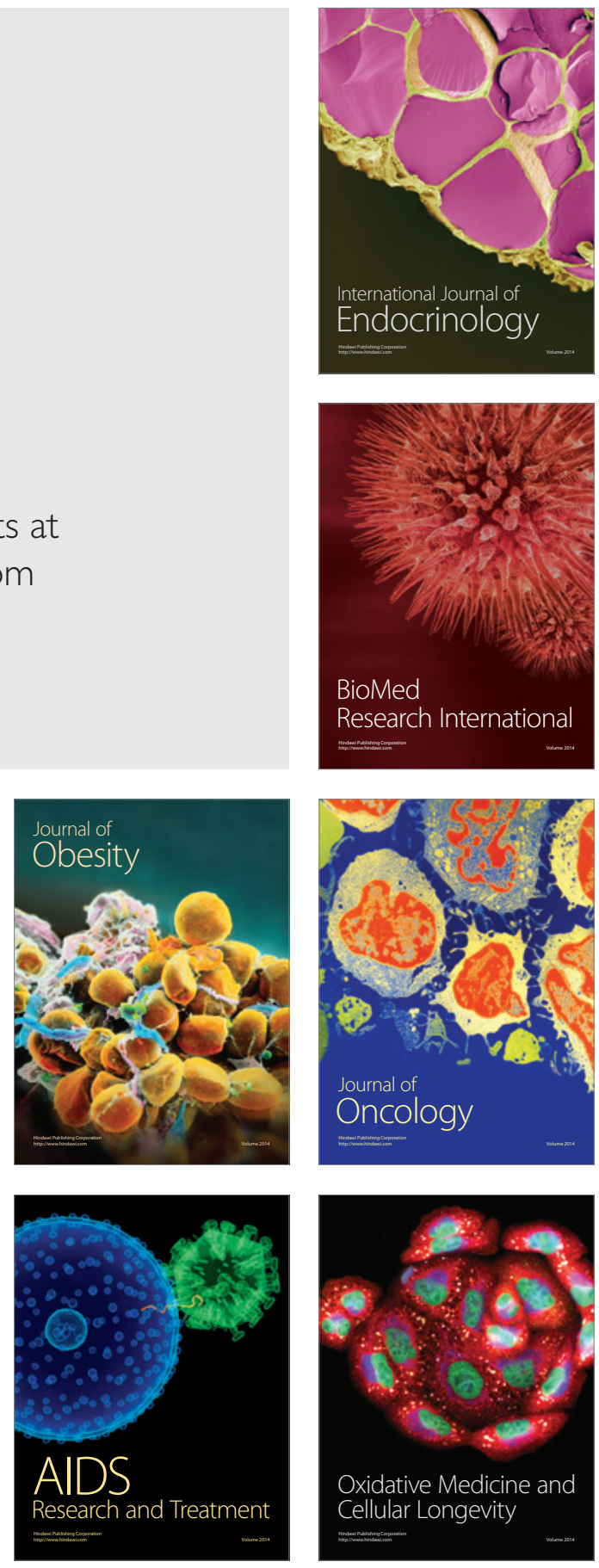